\title{
Less radiation in a radiology department than at home
}

\author{
Gerrit J. Kemerink • Marij J. Frantzen • Peter de Jong • \\ Joachim E. Wildberger
}

Received: 24 September 2010 /Revised: 16 November 2010/Accepted: 27 January 2011 /Published online: 15 February 2011

(C) The Author(s) 2011. This article is published with open access at Springerlink.com

\begin{abstract}
Objective To compare the total work-related radiation dose in our department of radiology with the dose in Dutch residences, taking $\mathrm{x}$-ray radiation, external natural radiation and radon into account.

Methods Annual doses due to exposure to x-rays and external natural radiation were derived from the measured personal dose equivalent $\left[\mathrm{H}_{\mathrm{p}}(10)\right]$ of 144 workers. Additionally, departmental ${ }^{222} \mathrm{Rn}$ concentrations were assessed over 1 year.

Results The departmental radon concentration was $5 \pm 1$ $\mathrm{Bq} / \mathrm{m}^{3}$, the personal dose equivalent due to external natural radiation $0.32 \pm 0.10 \mathrm{mSv} /$ year, considerably lower than the average Dutch residential values of $13.5 \mathrm{~Bq} / \mathrm{m}^{3}$ and $0.88 \mathrm{mSv} /$ year. As a consequence, working results in a lower dose than being at home as long as the x-ray-induced personal dose equivalent is lower than $1.25 \mathrm{mSv} / \mathrm{year}$, which was the case for 131 of the 144 radiological workers, as well as for the whole group on average.

Conclusions Working in our x-ray department results in a reduction in the collective effective dose, not an increase. The worldwide average radon concentration of $40 \mathrm{~Bq} / \mathrm{m}^{3}$, much higher than in the Netherlands, and the large decrease potentially achieved by the high ventilation rates common
\end{abstract}

There was no special funding for this study.

G. J. Kemerink $(\bowtie) \cdot$ M. J. Frantzen · J. E. Wildberger

Department of Radiology, Maastricht University Medical Center,

P. Debijelaan 25,

6229 HX Maastricht, The Netherlands

e-mail: gerrit.kemerink@mumc.nl

P. de Jong

Nuclear Research and consultancy Group (NRG),

PO Box 9034, 6800 ES Arnhem, The Netherlands in hospitals, suggest that even considerably higher reductions are possible in other countries.

Keywords Radiation dosimetry - Occupational exposure . Natural radiation · Healthy worker discussion - Optimisation of protection

\section{Introduction}

Working in a radiology department is commonly associated with an increased radiation dose due to exposure to x-rays. However, differences in natural radiation at work and at home should also be considered. Two main sources of natural radiation are relevant in this respect, radon progeny and external radiation, with the latter of terrestrial and cosmic origin [1].

Radon $\left({ }^{222} \mathrm{Rn}\right)$ occurs in the decay chain of ${ }^{238} \mathrm{U}[1]$. As a noble gas, it can exhale from soil and building materials. ${ }^{222} \mathrm{Rn}$ has short-lived non-gaseous decay products that tend to adhere to ambient aerosols. The concentration of the progeny in air is a balance between formation and removal by ventilation, decay and deposition. After inhalation, the alpha-emitting decay products readily settle in the airways of the lung, contributing heavily to the effective dose. External gamma radiation mainly comes from the daughter nuclides of the primordial radionuclides ${ }^{238} \mathrm{U}$ and ${ }^{232} \mathrm{Th}$, and from ${ }^{40} \mathrm{~K}$ [1]. Cosmic radiation at ground level has its origin in interactions of high energy particles from space with elements in the atmosphere [1]. It is attenuated by building materials, with transmission factors ranging from close to unity for wooden constructions to 0.3 for large multi-storey apartments [2]. Amazingly, data on the exposure caused by 
natural radiation are missing in nearly all fields of professional activity except mining [3].

Workers in radiology shield themselves against scattered $\mathrm{x}$-rays by wearing protective clothing. The protection factor, which is the ratio between the unshielded personal dosimeter reading $\mathrm{H}_{\mathrm{p}}(10)$ due to $\mathrm{x}$-rays and the shielded person's effective dose, depends on x-ray tube voltage, apron thickness and the use of a thyroid collar and is typically within the range of 10 to $100[4,5]$. The inverse, the so-called dose conversion factor $(0.01-0.1 \mathrm{mSv} / \mathrm{mSv})$, is also often used.

Because the apron protection factor is so high, a relatively small decrease in natural radiation or radon concentration in the department might "compensate" for a typical occupational $\mathrm{x}$-ray exposure. We therefore decided to quantify the radon concentration and the level of natural external and occupational radiation in our department. By comparing with residential values from a recent national survey, the difference between the natural radiation dose at work and at home could be estimated and weighed against the occupational $\mathrm{x}$-ray dose.

\section{Materials and methods}

\section{Department}

Our university hospital is a large six-storey concrete building with the department of radiology centrally located on the fourth floor. Floors consist of 30-cm-thick concrete, with inner walls of gypsum board. Walls of $\mathrm{x}$-ray rooms and barriers in front of operator desks in the department are shielded with $2 \mathrm{~mm}$ of lead or lead-equivalent glass. As a consequence, unless in the direct neighbourhood of an exposed patient, the level of scattered radiation is generally negligible.

In 2008 the department employed 144 radiological workers (radiologists, residents and radiographers). On a yearly basis about $150,000 \mathrm{x}$-ray procedures are performed, of which about 5,500 are interventions. Nuclear medicine studies and cardiological interventions are done in other departments.

${ }^{222} \mathrm{Rn}$ and $\mathrm{H}_{\mathrm{p}}(10)$ measurements

At various locations (reporting room, bucky room, CT operator room, canteen, waiting area) within the department, solid-state nuclear track-etch ${ }^{222} \mathrm{Rn}$ detectors (Gammadata Mätteknik, Uppsala, Sweden) were suspended from the ceiling at a height of about $2 \mathrm{~m}$. Additionally, in two air ventilation channels the incoming and outgoing air was monitored, as was the air in the unventilated basement of the hospital. The exposure time was 1 year. The results were compared with the data of a recent Dutch survey, covering about 1,000 newly built houses in the period 1994-2003 [6].

External exposure was monitored using thermoluminescence dosimeters (TLDs). In the Netherlands a single dosimeter is used, worn at the height of the chest on the shirt or the outside of protective clothing. These obligatory dosimeters contain two detectors of $\mathrm{Mg}$, Ti doped lithiumfluoride and are issued on a 4-weekly basis by NRG (Nuclear Research and consultancy Group, Arnhem, the Netherlands). Their readings are indicated as $\mathrm{H}_{\mathrm{p}}(10)_{\text {Reading }}$ and they cover the year 2008. Gammadata Mätteknik and NRG, who also took care of the read out, are certified for their services by the respective national authorities. The devices used for measuring the radon concentration and $\mathrm{H}_{\mathrm{p}}(10)$ were identical to those applied in the national survey $[6,7]$. Systematic differences therefore are thought to be negligible.

Protective clothing consists of wraparound aprons with overlapping front parts, generally with a separate thyroid collar. An average apron protection factor was estimated $[4,5]$.

Effective and collective (effective) doses

As some workers are hardly exposed to $\mathrm{x}$-rays, the readings of the personal dosimeter can also be used to estimate the dose in the department due to the external natural radiation, $\mathrm{H}_{\mathrm{p}}(10)_{\text {Nat_work. }}$ To keep the analysis manageable only two groups of workers of (beforehand) unknown size were assumed: one group that merely received external natural radiation, and one that was additionally exposed to x-rays. The number of exposed persons in the background-only group was modelled with a delta-function, that in the group exposed to both background and x-rays with an exponentially decreasing function. The inherent spread in TLD readings was taken into account by convoluting these two functions with a suitable Gaussian. In a least-squares fit procedure to the low-dose part of the dose distribution actually observed all parameters characterising the two functions and the Gaussian were obtained. The "position" of the (convoluted) delta function is $H_{p}(10)_{\text {Nat_work }}$.

The dose due to the occupational activities was then calculated according to:

$H_{p}(10)_{x-\text { rays }}=H_{p}(10)_{\operatorname{Re} a d i n g}-H_{p}(10)_{\text {Nat_work }}$

As some exposure to $\mathrm{x}$-rays when not wearing an apron is possible, applying the apron protection factor to the full $\mathrm{H}_{\mathrm{p}}(10)_{\mathrm{x} \text {-rays }}$ could result in an underestimation of the effective dose. To prevent this, the apron correction factor was not applied to the first $0.2 \mathrm{mSv}$. For the conversion of the various exposures into contributions to an annual 
effective dose, several conversion factors and other constants have been applied; these are given in Table 1. The occupational effective dose due to $\mathrm{x}$-ray exposure was then calculated as:

$E_{x-\text { rays }}=H_{P}(10)_{x-\text { rays }}$ if $H_{p}(10)_{x-\text { rays }} \leq 0.2 \mathrm{mSv}$, and

$E_{x-\text { rays }}=0.2 m S v+\frac{H_{p}(10)_{x-\text { rays }}-0.2 m S v}{A P F_{x-\text { xrays }}}$ if $H_{p}(10)_{x-\text { rays }}>0.2 \mathrm{mSv}$

where $\mathrm{APF}_{\mathrm{x} \text {-rays }}$ is the apron protection factor. The threshold of $0.2 \mathrm{mSv}$ is an arbitrary choice, but as it is nearly $50 \%$ of the average $\mathrm{x}$-ray dose (see below), it is likely a conservative estimate, as is the assumption that the $\mathrm{H}_{\mathrm{p}}(10)_{\mathrm{x} \text {-rays }}$ when $<0.2 \mathrm{mSv}$ results in an effective dose of the same magnitude.

The contribution to the effective dose due to the natural sources at work can be calculated according to:

$E_{\text {Nat_work }}=T_{\%} \cdot\left(C_{R n} \cdot F_{e q} \cdot C F_{R n} \cdot T+H_{p}(10)_{\text {Nat_work }} \cdot C F_{\text {Nat }}\right) \cdot P T F$

where $\mathrm{E}_{\text {Nat_work }}$ is the annual natural effective dose $(\mathrm{mSv})$, $\mathrm{C}_{\mathrm{Rn}}$ the concentration of ${ }^{222} \mathrm{Rn}$ in indoor air $\left(\mathrm{Bq} / \mathrm{m}^{3}\right)$, $\mathrm{H}_{\mathrm{p}}(10)_{\text {Nat_work }}$ the annual personal dose equivalent due to external natural radiation (mSv/year) and PTF the factor that accounts for part-time working. For all other factors see Table 1. After replacing the subscripts "work" with "home", Eq. 3 also applies for the dose in a dwelling, $\mathrm{E}_{\text {Nat home, }}$ with only the ${ }^{222} \mathrm{Rn}$ concentration and the annual personal dose equivalent being different with respective values of $13.5 \mathrm{~Bq} / \mathrm{m}^{3}$ [6] and $0.88 \mathrm{mSv} /$ year [7].

The net effective dose $\Delta \mathrm{E}$ was computed by summing the various contributions to the departmental effective dose and subtracting the average effective dose to an inhabitant of the Netherlands,

$\Delta E=E_{\text {Nat_work }}+E_{x-\text { rays }}-E_{\text {Nat_home }}$

in which $\mathrm{E}_{\mathrm{Nat} \text { work }}$ and $\mathrm{E}_{\mathrm{Nat} \_ \text {home }}$ were calculated according to Eq. 3. Collective doses were obtained by summing all individual doses.
When is the dose at work lower than at home?

After finding that both the level of radon and external gamma radiation were considerably lower within the department than in dwellings, we estimated the personal $\mathrm{x}$-ray dose equivalent that can be incurred without the effective dose becoming higher than it would be at home. To this purpose $\Delta \mathrm{E}$ in Eq. 4 was set to zero, and the equation was solved for $\mathrm{H}_{\mathrm{p}}(10)_{\mathrm{x} \text {-rays. }}$.

In countries where the obligatory dosimetry is performed with two dosimeters, one above and one below the apron, the following procedure might be followed to find the break-even exposure: Calculate $\mathrm{E}_{\mathrm{Nat} \_w o r k}$ and $\mathrm{E}_{\mathrm{Nat} \_ \text {home }}$ using Eq. 3. Any combination of dosimeter readings that results in an effective dose $\mathrm{E}_{\mathrm{x} \text {-rays }}$ equal to $\left(\mathrm{E}_{\mathrm{Nat} \_ \text {home }}-\mathrm{E}_{\mathrm{Nat} \_ \text {work }}\right)$ corresponds to a break-even exposure. $\mathrm{E}_{\mathrm{x} \text {-rays }}$ can be calculated from the two dosimeter readings with the algorithm that applies for the configuration in which the dosimeters are worn.

It seemed of interest to broaden the scope of our findings beyond our own hospital. To enable an estimation of a break-even $\mathrm{H}_{\mathrm{p}}(10)_{\mathrm{x} \text {-rays }}$ in other institutions, the following assumptions were made: (1) In a region with a given geology, all buildings have the same basic radon concentration, namely that of homes. (2) The radon concentration scales with the inverse of the ventilation rate. The ventilation rate is defined as the volume of air that enters a room per hour divided by the room volume. Assuming a value for the ratio of the ventilation rate in a hospital and a dwelling, an estimate of a regional $\mathrm{H}_{\mathrm{p}}(10)_{\mathrm{x} \text {-rays }}$ that undoes the protection against natural radiation at work can be calculated. Note that residential radon concentrations as required in this model are widely available.

\section{Results}

Radon

The results of the radon measurements are summarised in Table 2. The ventilation rate ranged from $3 \mathrm{~h}^{-1}$ in a

Table 1 Conversion factors and constants used in the calculation of the effective dose

\begin{tabular}{|c|c|c|c|c|}
\hline Abbreviation & Description & Value & Unit & Reference \\
\hline $\mathrm{CF}_{\mathrm{Rn}}$ & Conversion of ${ }^{222} \mathrm{Rn}$ concentration to effective dose & 9 & $\mathrm{nSv} /\left(\mathrm{Bq} \mathrm{h} \mathrm{m}{ }^{-3}\right)$ & [1] \\
\hline $\mathrm{F}_{\mathrm{eq}}$ & Equilibrium factor ${ }^{222} \mathrm{Rn}$ progeny & 0.4 & - & {$[1]$} \\
\hline $\mathrm{T}$ & Total hours per year & 8760 & $\mathrm{~h} / \mathrm{y}$ & - \\
\hline $\mathrm{T}_{\%}$ & Fractional working time $\left(1,752 \mathrm{~h}\right.$ year $\left.^{-1}\right)$ & 0.20 & - & - \\
\hline $\mathrm{CF}_{\mathrm{Nat}}$ & Conversion of $\mathrm{H}_{\mathrm{p}}(10)$ external natural radiation to effective dose & $0.605^{\mathrm{a}}$ & $\mathrm{mSv} / \mathrm{mSv}$ & {$[8]$} \\
\hline $\mathrm{APF}_{\mathrm{x} \text {-rays }}$ & Apron protection factor $\left[\mathrm{H}_{\mathrm{p}}(10)_{\mathrm{x} \text {-rays }} /\right.$ effective dose $]$ & 10 & $\mathrm{mSv} / \mathrm{mSv}$ & {$[4,5]$} \\
\hline
\end{tabular}

${ }^{a}$ Derived from the conversion factor from air-kerma to $\mathrm{H}_{\mathrm{p}}(10)$, which for external gamma radiation of around $800 \mathrm{keV}$ is $1.19 \mathrm{mSv} / \mathrm{mGy}$, and the conversion factor from air-kerma to effective dose of $0.72 \mathrm{mSv} / \mathrm{mGy}$ assuming isotropic radiation geometry [8] 
Table $2{ }^{222} \mathrm{Rn}$ concentration measured in the hospital

\begin{tabular}{lll}
\hline Location & Samples $(n)$ & ${ }^{222} \mathrm{Rn}\left(\mathrm{Bq} / \mathrm{m}^{3}\right)$ \\
\hline Air intake for ventilation, from roof & 1 & $3 \pm 1$ \\
Air exhaust & 1 & $7 \pm 1$ \\
X-ray department & 5 & $5 \pm 1$ \\
Basement of hospital & 2 & $26 \pm 10$ \\
\hline
\end{tabular}

reporting room (radon $7 \pm 1 \mathrm{~Bq} / \mathrm{m}^{3}$ ) to $10 \mathrm{~h}^{-1}$ in an $\mathrm{x}$-ray room $\left(5 \pm 1 \mathrm{~Bq} / \mathrm{m}^{3}\right)$. For comparison, the average Dutch residential radon concentration in living rooms is $13.5 \pm$ $0.5 \mathrm{~Bq} / \mathrm{m}^{3}$ ( $\left.n=1,011\right)$; the quoted uncertainty is the standard error of the mean, the only value reported [6].

\section{External dose}

Figure 1 shows the low-dose part of the distribution of the personal dosimeter readings, i.e., the $\mathrm{H}_{\mathrm{p}}(10)$ of 144 workers in 2008, together with the fit using the two components in which the spread in TLD readings was taken into account. The external natural radiation $\mathrm{H}_{\mathrm{p}}(10)_{\text {Nat_work }}$ was $0.32 \pm$ $0.10 \mathrm{mSv} /$ year. The Dutch average $\mathrm{H}_{\mathrm{p}}(10)_{\text {Nat_home }}$ is $0.88 \pm$ $0.11 \mathrm{mSv} /$ year [7].

\section{Occupational dose}

Protective clothing had a $\mathrm{Pb}$-equivalent thickness of 0.25 or $0.35 \mathrm{~mm}$ and normally included thyroid protection. Tube voltage during occupational exposure was nearly always below $100 \mathrm{kV}_{\mathrm{P}}$. A conservative estimate of the apron

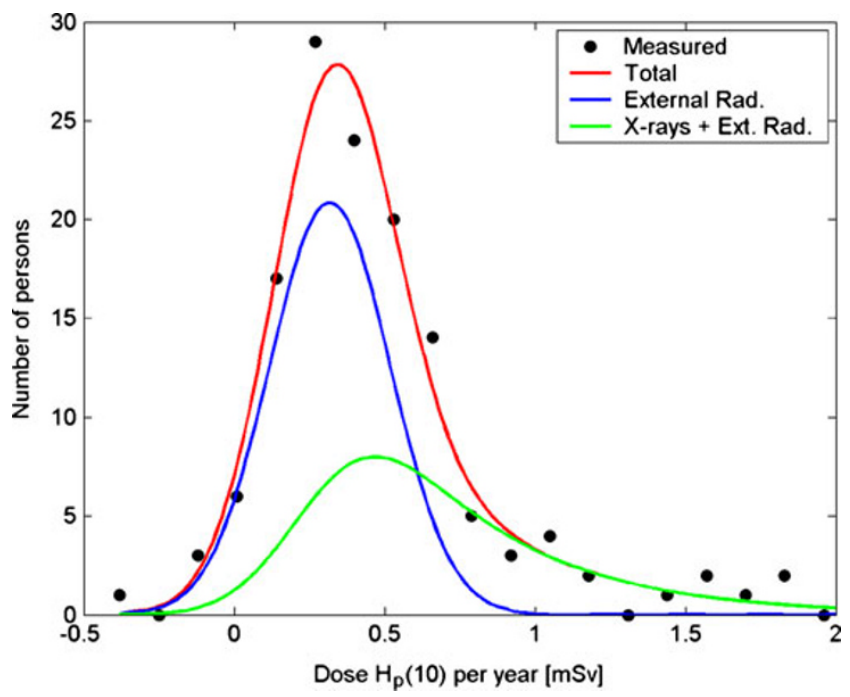

Fig. 1 Low-dose part of the distribution of the annual $\mathrm{H}_{\mathrm{p}}(10)$ in 2008 measured with personal dosimeters for 144 workers (circles), together with a fit of two components corresponding to dosimeters exposed to external radiation only (External rad.) and dosimeters exposed to both $\mathrm{x}$-rays and external natural radiation $(x$-rays + ext. rad $)$, respectively. The sum of the two components is also shown (Total) protection factor under these conditions is $10 \mathrm{mSv} / \mathrm{mSv}$ [4, 5]. Because of part-time employees, average working hours corresponded to $86 \%$ of a full-time job (thus $\mathrm{PTF}=0.86$ in Eq. 3).

The average annual personal dose-equivalent $\mathrm{H}_{\mathrm{p}}(10)_{\mathrm{x} \text {-rays }}$ was calculated according to Eq. 1 from the NRG readings and the local background as $0.44 \pm 0.11 \mathrm{mSv}$; the maximum was $11.6 \mathrm{mSv}$. The collective annual personal dose equivalent for $\mathrm{H}_{\mathrm{p}}(10)_{\mathrm{x} \text {-rays }}$ was $63 \mathrm{mSv}$. The annual collective occupational effective dose due to $\mathrm{x}$-rays ( $\left.\mathrm{E}_{\mathrm{x} \text {-rays }}\right)$ was $11.5 \mathrm{mSv}$; in this calculation Eq. 2 was used, and the results of the individual workers were summed. These low values show that current protection programs work well. The net collective effective dose $\Delta \mathrm{E}$ for all 144 radiological workers was found to be just negative (-3.5 mSv; Eq. 4).

Due to the lower level of radon and external gamma radiation in the department, a worker can incur an $H_{p}(10)$ due to x-rays of $1.25 \mathrm{mSv} /$ year above the apron before the net effective dose becomes positive. In 2008 only 13 of the 144 radiological workers received a dose higher than their not-working equals. All 13 were involved in interventions or fluoroscopic studies. The dose savings due to radon and external radiation were about equal in our department.

Finally, the line in Fig. 2 shows the x-ray dose that would make the effective dose in a department equal to that

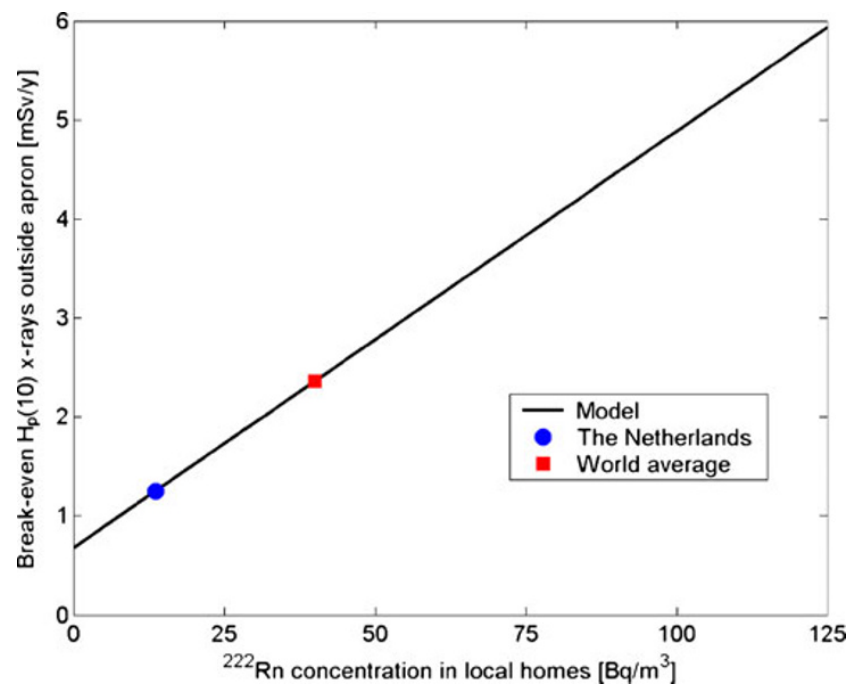

Fig. 2 Break-even dose as a function of the local residential radon concentration (line), with the break-even dose defined as the modelbased estimate of the personal dose equivalent to be incurred from $\mathrm{x}$-rays that undoes the decrease in radiation dose from natural sources within the hypothetical department. $H_{p}(10)$ due to external radiation in our department was $0.32 \mathrm{mSv} / \mathrm{year}$, in dwellings $0.88 \mathrm{mSv} / \mathrm{year}$. Ratio of the ventilation rates in the department and dwellings was set to 3 . The circle represents our hospital using the average Dutch radon concentration of $13.5 \mathrm{~Bq} / \mathrm{m}^{3}$; the square corresponds to the worldwide average of $40 \mathrm{~Bq} / \mathrm{m}^{3}$. Computations were done for a full-time job and wearing an apron and thyroid collar with a protection factor of $10 \mathrm{mSv} / \mathrm{mSv}$ during all $\mathrm{x}$-ray exposures 
in a home for a given regional residential radon concentration. The model is oversimplified, but nevertheless it should predict the general trend.

\section{Discussion}

In this study we included natural radiation in the calculation of the work-related radiation dose. Our data demonstrated that the effective dose for 131 of the 144 radiological workers was lower than it would have been if they had stayed at home, notwithstanding the low natural background in the Netherlands. Even the net collective effective dose was negative, implying an overall lower radiation dose at work than at home. To our knowledge this finding has not been reported before.

The low radon concentration in our department, a factor of 2 to 3 lower than in residences, is due to the high ventilation rate of $3-10 \mathrm{~h}^{-1}$, in combination with limited recirculation of the ventilation air. In the basement of the hospital, where active ventilation was absent, the radon concentration therefore increased substantially. In Dutch living rooms the air change rate is considerably lower than in the hospital, with an average value of $0.9 \mathrm{~h}^{-1}$ [6]. Moreover, there is a large difference in the origin of the ventilated air: in Dutch living rooms, only about $60 \%$ comes directly from outside with a low radon concentration (around $3 \mathrm{~Bq} / \mathrm{m}^{3}$ ). The remainder, however, mainly originates from the hallway with comparable concentrations to those in living rooms [6]. A further point of difference between dwellings and our hospital is that the radiology department is well isolated from the basement, which suggests that contribution from the soil is negligible.

The low external natural dose rate is partly due to high attenuation of cosmic and terrestrial radiation by the $30-\mathrm{cm}$ concrete floors of the hospital. Owing to self-absorption, the thickness of the concrete floors (which also contain some activity) does not seriously affect the gamma exposure rate $[9,10]$. As all internal partition walls are made of gypsum panels, little extra contribution to the dose rate from these is expected [9]. Moreover, some of the gypsum walls are clad with $2 \mathrm{~mm}$ of lead, also providing some additional shielding against background gamma radiation.

Our results on radon are qualitatively similar to those recently reported by Whicker and McNaughton [3]. These authors found lower radon concentrations in offices than in homes, the ratio also being about 3 , although the residential radon concentrations in Los Alamos (about $75 \mathrm{~Bq} / \mathrm{m}^{3}$ ) were substantially higher than in the Netherlands. The authors also attribute the ratio of 3 to differences in the ventilation rate.

As studies similar to ours are lacking, conclusions for other hospitals can be tentative at best. The shielding of cosmic and terrestrial radiation might be comparable for other hospitals, provided they are large. However, the reduction in the radon dose could in principle be much higher. The worldwide average radon concentration is about $40 \mathrm{~Bq} / \mathrm{m}^{3}$ [1], and because regulations require most hospital rooms to have high ventilation rates, the absolute reduction in radon concentration can be high. This will be illustrated by an example that applies to some of our workers. For the village of Eijsden, $6 \mathrm{~km}$ from the hospital, residential radon concentrations with an average of $46 \mathrm{~Bq} / \mathrm{m}^{3}$ have been reported [11]. Workers living in this village can have an annual x-ray dosimeter reading of $3.2 \mathrm{mSv}$ without surpassing the dose they would receive in staying at home. In the light of the worldwide average of $40 \mathrm{~Bq} / \mathrm{m}^{3}$, the result for Eijsden is likely to be more representative for many countries than that of the Netherlands as a whole. Here it might be emphasised that the break-even dose and the slope in Fig. 2 scale with the apron protection factor. We used a value of 10 , a rather conservative estimate according to the study of Siiskonen et al. [4], who reported values between 44 and 258 for a $0.35 \mathrm{~mm} \mathrm{~Pb}$ apron and thyroid protection.

This study did not include the effect of the daughters of thoron $\left({ }^{220} \mathrm{Rn}\right.$, the radon isotope in the ${ }^{232} \mathrm{Th}$ series); however, taking this into account is bound to increase the difference between well ventilated and poorly ventilated spaces even further. Moreover, the ICRP [12] recently published a "Statement on Radon" announcing a revision of dose conversion coefficients: "The Commission advises that the change is likely to result in an increase in effective dose per unit exposure of around a factor of two." Application of such new dose coefficients will strengthen the conclusions of this study even further.

Although our study is small and in need of confirmation at other institutions, a few concluding observations might be made:

1. Optimisation of occupational radiation protection in radiology was clearly successful. Slightly more than a century ago radiology started with radiation casualties, loss of fingers and other dreadful effects caused by normal (non-interventional) x-ray imaging; now the dose for the same work can be lower than that at home. This is something to cherish (but it should not reduce radiation awareness).

2. Our findings should be good news for all radiological workers, and especially for the small but non-negligible group of workers with radiophobia.

3. As occupational doses are low today, natural radiation at work and at home should be taken into account in risk assessments of radiological workers, which has not been done so far (see for example Yoshinaga et al. [13]). 
4. Differences in natural radiation appear potentially relevant in the so-called healthy worker discussion [13], in addition to x-ray exposure and socio-economic factors that have an impact on health.

5. According to the ICRP [14] the principle of optimisation of protection applies to all exposure situations. As optimisation should take economic and societal factors into account, this could potentially imply that a worker's radiation protection could most easily be further optimised at the worker's home.

6. With respect to the level of "dose constraints" [14] for radiological workers, the "break-even dose" might possibly serve as a natural reference for a large group of radiological workers.

Open Access This article is distributed under the terms of the Creative Commons Attribution Noncommercial License which permits any noncommercial use, distribution, and reproduction in any medium, provided the original author(s) and source are credited.

\section{References}

1. United Nations Scientific Committee on the Effects of Atomic Radiation (2000) UNSCEAR 2000 report to the general assembly, with scientific annexes. Vol. I, Annex B, exposures from natural radiation sources. United Nations, New York

2. Miller KM, Beck HL (1984) Indoor gamma and cosmic ray exposure rate measurements using a Ge spectrometer and pressurised ionisation chamber. Radiat Prot Dosim 7:185-189
3. Whicker JJ, McNaughton MW (2009) Work to save dose: contrasting effective dose rates from radon exposure in workplaces and residences against the backdrop of public and occupational regulatory limits. Health Phys 97:248-256

4. Siiskonen T, Tapiovaara M, Kosunen A, Lehtinen M, Vartiainen E (2007) Monte Carlo simulations of occupational radiation doses in interventional radiology. Br J Radiol 80:460-468

5. Netherlands Commission on Radiation Dosimetry (2008) Code of practice for personal dosimetry of professionals wearing protective clothing during radiological procedures. Report 19. Netherlands Commission on Radiation Dosimetry, Delft

6. Bader S, Dekkers SAJ, Blaauboer RO (2010) Radiation dose in newly-built dwellings in the Netherlands. RIVM report 610790009/2010 (in Dutch). National Institute for Public Health and the Environment, Bilthoven

7. de Jong P, van Dijk JWE (2009) Analysis of the external dose rate in dwellings. VERA survey 2006. Report NRG-K5098/09.97299 (in Dutch). National Institute for Public Health and the Environment, Bilthoven

8. ICRP (1997) Publication 74: conversion coefficients for use in radiological protection against external radiation. Annals of the ICRP, volume 26/3. Elsevier Science, Oxford

9. de Jong P, van Dijk W, van der GraafER, de Groot TJ (2006) National survey on the natural radioactivity and $222 \mathrm{Rn}$ exhalation rate of building materials in the Netherlands. Health Phys 91:200-210

10. de Jong P, van Dijk W (2008) Modeling gamma radiation dose in dwellings due to building materials. Health Phys 94:33-42

11. Albering HJ, Hoogewerff JA, Kleinjans JC (1996) Survey of 222Rn concentrations in dwellings and soils in the Dutch Belgian border region. Health Phys 70:64-69

12. ICRP (2009) Statement on radon. International Commission on Radiological Protection, ref 00/902/09. http://www.icrp.org/icrp_ra don.asp. Accessed September 23, 2010

13. Yoshinaga S, Mabuchi K, Sigurdson AJ et al (2004) Cancer risks among radiologists and radiologic technologists: review of epidemiologic studies. Radiology 233:313-321

14. ICRP (2007) Publication 103: the 2007 recommendations of the ICRP. Annals of the ICRP, volume 37/2-4. Elsevier Science, Oxford 